\title{
Effect of Various Parameters on the Growth and Ethanol Production by Yeasts Isolated from Natural Sources
}

\author{
Shafkat Shamim Rahman, Md. Mahboob Hossain, Naiyyum Choudhury \\ Biotechnology and Microbiology programs, Department of MNS, BRAC University, Mohakhali, Dhaka-1212
}

\begin{abstract}
Two ethanol fermenting Saccharomyces cerevisiae were isolated from date juice and grapes and grown in YEPD medium. They were characterized for alcoholic fermentation using sugarcane molasses and their growth conditions were optimized with respect to $\mathrm{pH}$ and sugar concentration. Results revealed a temperature of $30^{\circ} \mathrm{C}$, pH 6.0 and $6.5 \%$ sugar concentration as optimum for fermentation. Stress tolerance tests showed that date juice isolate was highly tolerant to temperature, $\mathrm{pH}$ and high ethanol concentration in the medium. Under optimized conditions, $S$. cerevisiae isolated from date-juice produced $7.75 \%$ of ethanol in molasses as estimated by Conway method.
\end{abstract}

Key words: Ethanol, yeast, biofuel, Saccharomyces cerevisiea

\section{Introduction}

Over the last few decades, the negative impacts of fossil fuel on the environment and consequent global warming, progressive demand for energy, inevitable depletion of the world's energy supply, and the unstable oil market (such as the energy crisis of the 1970s) have renewed the interest in searching for alternative fuels ${ }^{1}$. The alternative fuels are expected to satisfy several requirements including substantial reduction of greenhouse gas emission, worldwide availability of raw materials, and capability of being produced from renewable feedstocks ${ }^{2}$. Production of bio-ethanol through fermentation is a potential alternative to traditional fossil fuel and can be utilized as a sole fuel in cars with dedicated engines or in fuel blends. Ethanol is currently produced from sugars, starches and cellulosic materials. The first two groups of raw materials are currently the main resources for ethanol production, but concomitant growth in demand for human feed similar to energy could make them potentially less competitive and perhaps expensive feedstocks in the near future, leaving the cellulosic materials as the only potential feedstock for production of ethanol ${ }^{3}$.

In this study, yeast was isolated from date juice and grapes, fermentation was carried out in molasses and the characteristics of the yeast isolates in terms of ethanol production, temperature and $\mathrm{pH}$ tolerance were also analyzed.

\section{Materials and methods}

\section{Isolation of yeast}

The yeasts were isolated from rotten grapes and date-juice collected from markets around Dhaka. First the sample was grown in Yeast extract Peptone Dextrose (YPD) broth for 48 hour and then streaked on YPD agar medium. Suspensions from suspected colonies were observed under the light microscope to get desired yeasts. Yeast isolates which yielded more ethanol in preliminary screening were then identified by biochemical tests ${ }^{4}$.

Identification of yeast isolates

The yeast isolates were characterized based on their cultural characteristics (colony morphology, pigment, elevation, edge and surface appearance). Morphological and biochemical characterization of the isolated yeasts was performed according to Boboye and Dayo-Owoyemi ${ }^{5}$.

\section{Maintenance of the Culture}

The yeast isolates were cultured and maintained in Yeast Maintenance Medium (YMM, Difco, UK) and Yeast extract Peptone Dextrose medium (YPD, Difco, U K).

\section{Inoculum Development}

The yeast inoculum was prepared by transferring 2 to 3 yeast colonies in molasses broth and growing them in $250 \mathrm{ml}$ conical flask containing $25 \mathrm{ml}$ media at $30^{\circ} \mathrm{C}$ at $130 \mathrm{rpm}$ for 48 hours.

\section{Cell count and Maintenance}

A hematocytometer was used to determine yeast cell counts in each conical flask. A $1 \mathrm{ml}$ inoculum broth sample was serially diluted with a sterile saline solution $(0.89 \% \mathrm{w} / \mathrm{v} \mathrm{NaCl})$ to a point where a reasonable number of cells could be counted ${ }^{6}$. Mostly the cell count recorded was $10 \mathrm{v}$ cells $/ \mathrm{ml}$ or a fraction higher.

\section{Pretreatment of molasses}

The molasses were collected from local market and used as nutrient source for the Yeast. Molasses were pretreated with 
sulfuric acid to remove particles, dirt and kill unwanted microbes and urea was used as nitrogen source. $250 \mathrm{~g}$ molasses was diluted with water to bring the final volume to $1 \mathrm{~L}$ and $0.10 \mathrm{~g}$ urea and 0.30 $\mathrm{ml}$ concentrated sulfuric acid was added and heated to boiling. This was kept standing for couple of hours before use.

\section{Fermentation}

Autoclaved molasses fermentation broth $(10 \mathrm{ml})$ was inoculated with 48 hours grown slant culture of $S$. cerevisiae and the tube was placed in a rotary incubator at $30^{\circ} \mathrm{C}$ with vigorous shaking (180 rpm) to form a homogeneous suspension.

$250 \mathrm{ml}$ fermentation media was taken into $500 \mathrm{ml}$ Erlenmeyer flasks and inoculated with homogenous suspension of yeast under aseptic condition. The flasks were incubated at different temperatures under both non-shaking and shaking condition.

\section{Ethanol production procedure from fermentation of molasses}

$250 \mathrm{ml}$ of sterile pretreated fermentation media was taken into $500 \mathrm{ml}$ Erlenmeyer flasks and $1000 \mu \mathrm{l}$ of $24 \mathrm{~h}$ old culture $\left(10^{8} \mathrm{CFU}\right.$ $\mathrm{ml}^{-1}$ ) was added and incubated for 48 hours with different condition. The fermentation was carried out at varying temperature, $\mathrm{pH}$, reducing sugar concentration and agitation.

\section{Stress tolerances}

\section{Thermotolerance}

Temperature is one of the most important factors that affect ethanol production by yeast using molasses as a carbon source ${ }^{7}$. The fermentation process is always accompanied with evolution of heat that raises the temperature of the fermenter. YPD liquid medium was used for detecting thermo-tolerance and growth in liquid media of selected yeast isolates. Ten $\mathrm{ml}$ portion of the medium was taken in McCartney tubes and inoculated with 48 hours old selected yeast isolates. The initial optical density of each tube was recorded using a spectrophotometer at $600 \mathrm{~nm}$ against the medium as blank. All cultures were incubated at $25^{\circ} \mathrm{C}$, $30^{\circ} \mathrm{C}, 37^{\circ} \mathrm{C}, 40^{\circ} \mathrm{C}$ and $44^{\circ} \mathrm{C}$ for 2 days to observe thermo-tolerance of the yeast isolates. The increase in optical density in each tube was recorded as evidence of growth. Besides this, growth on YPD agar media at $25^{\circ} \mathrm{C}, 30^{\circ} \mathrm{C}, 37^{\circ} \mathrm{C}$ and $40^{\circ} \mathrm{C}$ was also observed to ensure thermo-tolerance.

\section{Ethanol tolerance}

One $\mathrm{ml}$ of various concentrations of absolute ethanol varying from 5 to $25 \%(\mathrm{v} / \mathrm{v})$ were added to different flasks of Molasses fermentation medium to constitute varying percentages of ethanol: $5 \%, 10 \%, 12 \%, 15 \%, 18 \% 20 \%$ and $25 \%(\mathrm{v} / \mathrm{v})$. Forty mililiter portion of the medium was taken in $125 \mathrm{ml}$ flask and then inoculated with selected thermo-tolerant yeasts. The initial optical density of each flask was read in a spectrophotometer at $600 \mathrm{~nm}$ against the medium as blank. All cultures were incubated at $40^{\circ} \mathrm{C}$ for 5 days. The increase in optical density in a flask was recorded as evidence of growth. The concentration of alcohol at which the growth of yeasts was just inhibited was assessed as the ethanol tolerance of yeasts.

\section{pH tolerance}

YPD liquid medium was used for detecting the ability of the yeast isolates to grow at different $\mathrm{pH}$ values. Sterilized YPD broth at different $\mathrm{pH}$ was prepared. Each test tube contained $13 \mathrm{ml}$ of YPD media with different $\mathrm{pH}$. Then each was inoculated with half loop-full of yeast colony. The initial optical density was measured at $600 \mathrm{~nm}$ and the tube was incubated at $30^{\circ} \mathrm{C}$ for $48 \mathrm{hrs}$. After 48 hrs cell density was again recorded at $600 \mathrm{~nm}$ for growth. Blank media was used as a negative control for growth.

\section{Osmotolerance:}

Growth impairment under conditions of high osmotic strength is often associated with defects in the cell wall or components of the cytoskeleton ${ }^{8}$. YPD broth was prepared containing $6 \%, 9 \%, 12 \%$, $15 \%, 18 \%$ and $20 \%$ of $\mathrm{NaCl}$. Each test-tube contained $13 \mathrm{ml}$ of YPD medium with appropriate concentration of salt. Blank medium was used as negative control of growth. Each test tube was inoculated with half loop-full of yeast colony. Initial optical density was measured at $600 \mathrm{~nm}$ and the cells were incubated at $30^{\circ} \mathrm{C}$ for $48 \mathrm{hr}$. After $48 \mathrm{hr}$ cell density was again recorded at $600 \mathrm{~nm}$.

\section{Estimation of reducing sugars}

The concentration of reducing substances (sugar) of the fermentation medium was estimated by dinitrosalicylic acid (DNS) method $^{9}$. A double beam UV/VIS -scanning spectrophotometer (Model-TGOU, Perkin Elmer,UK) was used for measuring absorbance at $540 \mathrm{~nm}$.

\section{Estimation of ethanol}

The amount of ethanol was determined using the Conway method ${ }^{10}$. One $\mathrm{ml}$ of fermented solution was diluted 250, 500 and 1000 times with distilled water to estimate ethanol concentration and one $\mathrm{ml}$ of the diluted solution was taken as a sample. A Conway unit was used for ethanol detection by the following procedure.

One $\mathrm{ml}$ potassium dichromate was placed into the center of the Conway unit. The sample was placed around the center. The Conway unit was then covered by a glass plate for 24 hours for reaction. The water and ethanol slowly evaporated, came in contact with Potassium dichromate and then became oxidized. One Conway unit was used as a blank as a blank containing $1 \mathrm{ml}$ distilled water. After allowing reaction for 24 hours the sample was titrated against $0.1 \mathrm{~N} \mathrm{Na}_{2} \mathrm{SO}_{3}$.

\section{Results and Discussion}

\section{Identification of yeast isolates}

Based on the colony characteristics of (white and creamy texture) ovoid microscope shape, the presence of ascospore and budding pattern (multipolar), carbohydrate fermentation test, the selected isolates were found to belong to Saccharomyces $s p$.

\section{Fermentation of carbohydrates}

In this study, Saccharomyces cerevisiae showed variation in utilization of seven different sugars (Table 1). The date-juice isolate 
utilized glucose, sucrose, fructose, lactose, maltose and trehalose but failed to grow on xylose. The isolate obtained from grapes utilized glucose, sucrose, fructose, lactose and trehalose but failed to grow on maltose and xylose.

Table 1. Fermentation of different carbohydrates by selected date-juice isolate of $S$. cerevisiae.

\begin{tabular}{lcc}
\hline Carbohydrate & Before fermentation & After fermentation \\
\hline Glucose/ Dextrose & Pink & + (yellow), gas \\
Sucrose & Pink & + (yellow), gas \\
Maltose & Pink & + (yellow), gas \\
Lactose & Pink & + (yellow), gas \\
Fructose & Pink & + (yellow), gas \\
Xylose & Pink & - (no color change) \\
Trehalose & Pink & +(yellow), gas formed \\
\hline
\end{tabular}

\section{Stress tolerance of isolated yeasts}

Thermotolerance: Five YPD agar containing plates were streaked with Yeast colonies and incubated for 48 hours at $25^{\circ} \mathrm{C}, 30^{\circ} \mathrm{C}$, $37^{\circ} \mathrm{C}, 40^{\circ} \mathrm{C}$ and $44^{\circ} \mathrm{C}$. The date-juice isolate of yeast was able to grow at $25^{\circ}-40^{\circ} \mathrm{C}$ but the grape isolate failed to grow at $44^{\circ} \mathrm{C}$. To confirm the results obtained from solid media, thermotolerance study was repeated in liquid media. The results are shown in the given Table 3. It is evident that the Date-juice isolate was slightly thermo-tolerant as it had ability to grow up to $44^{\circ} \mathrm{C}$ and the most suitable condition for growth of the yeast was found to be $30^{\circ} \mathrm{C}$.

Table 2. Fermentation of different carbohydrates by selected grape isolate of S. cerevisiae.

\begin{tabular}{lcc}
\hline Carbohydrate & Before fermentation & After fermentation \\
\hline Glucose/ dextrose & Pink & + (yellow), gas \\
Sucrose & Pink & + (yellow), gas \\
Maltose & Pink & - (no color change) \\
Lactose & Pink & + (yellow), \\
Fructose & Pink & + (yellow), \\
Xylose & Pink & - (no color change) \\
Trehalose & Pink & + (yellow), \\
\hline
\end{tabular}

Ethanol tolerance: The two isolates DJ and G isolate were selected for screening of ethanol tolerance. It was found that the isolate could grow up to $20 \%$ ethanol containing liquid YEPD media. Maximum growth for the date-juice (DJ isolate) was observed at $5 \%$ ethanol containing media, but for the grape isolate growth occurred at $10 \%$ ethanol. Growth were recorded at 5\%, $10 \%$, $12 \%, 15 \%, 18 \%, 20 \%$, and $25 \%$ of ethanol containing liquid media and O.D was recorded (Table 4).

Table 3. Growth of date-juice and grap isolate at different temperatures in liquid media.

\begin{tabular}{lcccc}
\hline Temperature & Strain & O.D.at Inoculation & O.D.after 24 hours & O.D.after 48 hours \\
\hline $25^{\circ} \mathrm{C}$ & Date-juice & 0.559 & 1.501 & 2.290 \\
& Grapes & 0.519 & 1.424 & 2.063 \\
$30^{\circ} \mathrm{C}$ & Date-juice & 0.515 & 1.848 & 2.311 \\
& Grapes & 0.441 & 1.790 & 2.162 \\
$37^{\circ} \mathrm{C}$ & Date-juice & 0.671 & 1.744 & 2.058 \\
& Grapes & 0.523 & 1.025 & 1.901 \\
$40^{\circ} \mathrm{C}$ & Date-juice & 0.465 & 1.456 & 1.918 \\
& Grapes & 0.350 & 0.301 & 1.261 \\
$44^{\circ} \mathrm{C}$ & Date-juice & 0.511 & 0.693 & 0.802 \\
& Grapes & 0.687 & 0.530 & 0.471 \\
\hline
\end{tabular}

Table 4. Growth of date-juice and grape isolates in different concentrations of ethanol in the media.

\begin{tabular}{lcccc}
\hline Ethanol \% & Isolate & O.D.at Inoculation & O.D.after 24 hours & O.D.after 48 hours \\
\hline 5 & Date-juice & 0.364 & 0.654 & 1.920 \\
& Grape & 0.433 & 0.891 & 1.403 \\
10 & Date-juice & 0.365 & 1.296 & 1.825 \\
& Grape & 0.445 & 0.638 & 1.452 \\
12 & Date-juice & 0.247 & 0.588 & 1.206 \\
& Grape & 0.336 & 0.409 & 0.560 \\
15 & Date-juice & 0.352 & 0.683 & 0.833 \\
& Grape & 0.246 & 0.288 & 0.305 \\
18 & Date-juice & 0.269 & 0.670 & 1.293 \\
& Grape & 0.244 & 0.283 & 0.309 \\
20 & Date-juice & 0.290 & 0.313 & 0.384 \\
& Grape & 0.192 & 0.277 & 0.503 \\
& Date-juice & 0.220 & 0.201 & 0.166 \\
& Grape & 0.259 & 0.237 & 0.109 \\
\hline
\end{tabular}


pH tolerance: The ethanol producing isolates were observed to have ability to grow at wide ranges of $\mathrm{pH}$. At $\mathrm{pH} 2$ the growth was not remarkable but the isolates survived the high acidic condition. They withstood the alkaline condition up to $\mathrm{pH} 10$. Maximum growth was seen at $\mathrm{pH}$ 5. After 48 hours, cell density was recorded at $600 \mathrm{~nm}$ (Table 5). The optimal $\mathrm{pH}$ range for growth of the test yeast was found to vary from $\mathrm{pH} 4.0$ to 6.0, depending on temperature, the presence of oxygen, and the strain of yeast. Similar observation was reported for $\mathrm{pH}$ tolerance of yeasts ${ }^{11}$.This is possibly due to the optimum $\mathrm{pH}$ value for the activity of plasma membrane-bound proteins, including enzymes and transport proteins ${ }^{11}$.

Osmotolerance: YEPD broth was prepared containing 6\%, 9\%, $12 \%, 15 \%, 18 \%$, and $20 \%$ of $\mathrm{NaCl}$. Growth was recorded at these salt concentrations by measurement of O.D at $600 \mathrm{~nm}$ (Table 6)

The results showed that both isolates were resistant to high concentration of $\mathrm{NaCl}$ indicating osmoltolerance. Both isolates showed highest growth at $6 \% \mathrm{NaCl}$ containing media and tolerated up to $12 \% \mathrm{NaCl}$ in the medium. Growth gradually declined at still higher concentration of salt (Table 6).

Kinetics of ethanol fermentation by the isolates under optimum growth condition

S. cerevisiae is capable of very rapid rates of glycolysis and ethanol production under optimal condition. The date juice isolated strain was grown in molasses media under optimum sugar concentration, temperature and two different $\mathrm{pH}$ and the results are shown in Figures 1 and 2. The production of alcohol was null at the initial stage of fermentation where the $\mathrm{pH}$ was fixed at 5 (Figure 1). After 24 hours, the level of glucose decreased and significant amount of ethanol was produced. Maximum alcohol was produced after 48 to72 hours of fermentation. Earlier experiments suggested more Ethanol was produced in shaking than non-shaking state ${ }^{12}$. After 96 hours of incubation under shaking condition fermentation yielded a maximum of $7.75 \%$ ethanol.

Table 5. Growth of selected yeast isolates in liquid media at different $\mathrm{pH}$

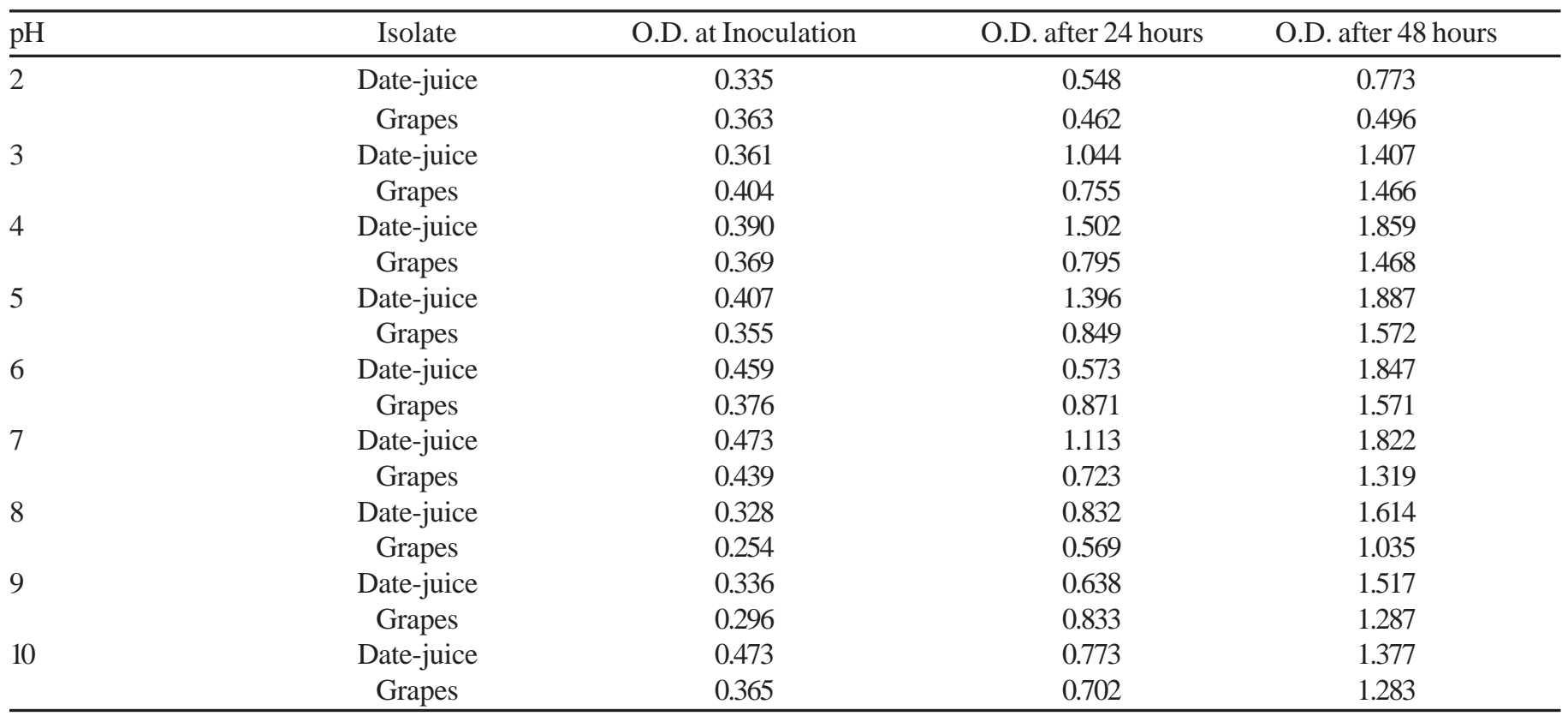

Table 6. Growth in different concentrations of $\mathrm{NaCl}$ in the liquid media

\begin{tabular}{lcccc}
\hline \% of $\mathrm{NaCl}$ & Isolate & O.D. at Inoculation & O.D. after 24 hours & O.D. after 48 hours \\
\hline 6 & Date-juice & 0.206 & 0.569 & 1.325 \\
& Grapes & 0.221 & 0.343 & 0.411 \\
9 & Date-juice & 0.209 & 0.379 & 0.661 \\
& Grapes & 0.226 & 0.267 & 0.315 \\
12 & Date-juice & 0.258 & 0.329 \\
& Grapes & 0.218 & 0.249 & 0.301 \\
15 & Date-juice & 0.222 & 0.267 & 0.302 \\
18 & Grapes & 0.242 & 0.254 & 0.294 \\
& Date-juice & 0.260 & 0.281 & 0.314 \\
& Grapes & 0.252 & 0.286 & 0.351 \\
& Date-juice & 0.224 & 0.332 & 0.356 \\
\end{tabular}




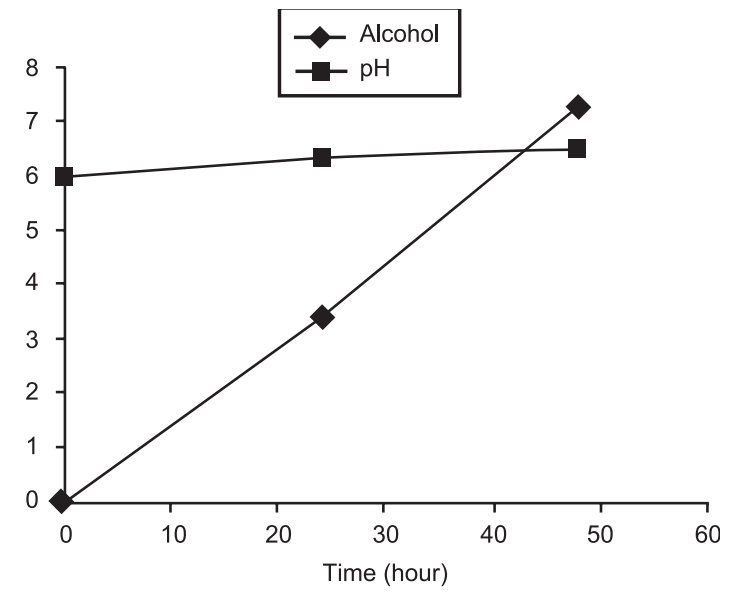

Figure 1. Fermentation Kinetics of date-juice isolate in shake flasks at $6.5 \%$ reducing sugar and $p H 6-.0$ at $30^{\circ} \mathrm{C}$ temperature.

At $\mathrm{pH} 5$ glucose diminished rapidly and ethanol production rate was slow (Figure 2).
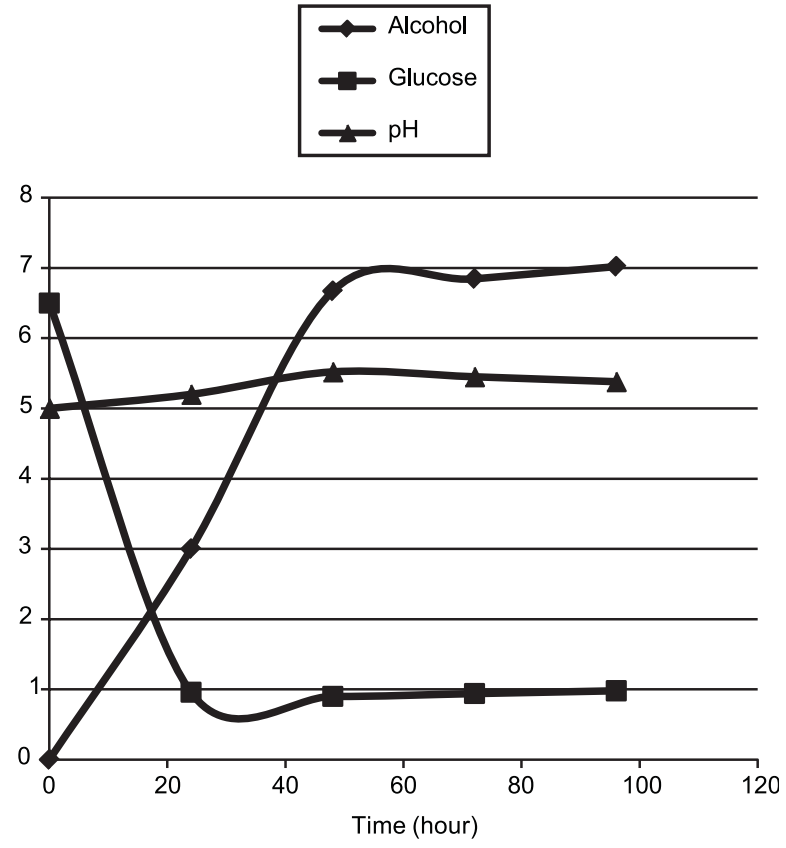

Figure 2. Fermentation kinetics of date-juice isolate in shake flasks at $6.5 \%$ reducing sugar and $\mathrm{pH} 5.0$ at $30^{\circ} \mathrm{C}$ temperature.

Glucose concentration is pivotal in ethanol fermentation. Various sets of parameters showed that production of ethanol was favorable at $6.5 \%$ glucose (Table 7 ). In a similar study in Bangladesh five isolates were reported to produce alcohol by fermenting molasses at wide range of temperature $\left(25-37^{\circ} \mathrm{C}\right)$. The production was maximal at $30^{\circ} \mathrm{C}$ after 48 hours of incubation. Using varying glucose concentrations (2.3 to $5.9 \%$ ) as substrate in the fermented media alcohol production rate was reported to be maximal up to 36 hours $^{13}$.
Study showed the logarithmic relationship between time of fermentation and initial concentrations of sugar ${ }^{14}$.

Table 7. Fermentation by date-juice yeast isolate in shake flasks at different reducing sugar and $\mathrm{pH}$ levels at $30^{\circ} \mathrm{C}$ temperature.

\begin{tabular}{lccccc}
\hline Glucose (\%) & $\mathrm{pH}$ & \multicolumn{4}{c}{ Ethanol production (\%) } \\
\cline { 2 - 6 } & & $24 \mathrm{hr}$ & $48 \mathrm{hr}$ & $72 \mathrm{hr}$ & $96 \mathrm{hr}$ \\
\hline 6.5 & 5 & 3 & 6.67 & 6.845 & 7.02 \\
6.5 & 6 & 3.73 & 7.75 & 7.205 & 6.66 \\
7 & 5 & 2.27 & 6.15 & 5.19 & 5.19 \\
7 & 6 & 2.07 & 6.83 & 6.66 & 6.66 \\
\hline
\end{tabular}

In another experiment, ethanol production in the fermentation broth was increased with the addition of $5 \%(\mathrm{v} / \mathrm{v})$ glucose but decreased beyond that. The final glucose utilization in the fermentation broth was found to be $5 \%(\mathrm{v} / \mathrm{v})$, but above this concentration the final glucose utilization became quite appreciable ${ }^{15}$. The maximum specific growth rate and maximum ethanol concentration increased with an increase of glucose concentration from $5 \%(\mathrm{v} / \mathrm{v})$. A reduction of ethanol production and growth of yeast were detected when glucose concentration was greater than $5 \%(\mathrm{v} / \mathrm{v})^{15}$. Interestingly, similar findings were observed in the present study in which $6.5 \%$ and $7 \%$ glucose concentration proved to be the optimum sugar concentration for ethanol production. At 7.5\% concentration of glucose production of ethanol plummeted. Date-juice isolates were found to be the most productive isolates than the grapes isolates.

Hydrogen ion concentration has a significant influence on industrial fermentation due as much to its importance in controlling bacterial contamination as its effect on yeast growth, fermentation rates and by-product formation ${ }^{11}$. The best ethanol yields are generally obtained at $\mathrm{pH}$ 4.5-4.7. At higher $\mathrm{pH}$, more glycerol and organic acids are formed at the expense of ethanol ${ }^{16}$.pH 6.0 was found to be more suitable condition than $\mathrm{pH} 5.0$ for the production of ethanol in this study.

\section{Conclusion}

Yeast isolates from date and grapes were tested for fermentation of carbohydrates. Date-juice isolate was capable of fermenting six out of the seven sugars tested. Glucose, Sucrose, Fructose, Lactose, Maltose and Trehalose were successfully fermented by this isolate but it failed to ferment Xylose. The Grapes isolate failed to ferment Maltose and Xylose, but utilized the other five carbohydrates, which proved the identity that both of the microorganisms are Saccharomyces cerevisiae.

Both isolates were screened for ethanol tolerance and showed up to $25 \%$ ethanol tolerance in YEPD liquid growth media. A slow growth rate was observed at $10-20 \%$ ethanol containing media.

The optimal $\mathrm{pH}$ range for growth of yeast can vary from $\mathrm{pH} 4.0$ to 6.0 , depending on temperature, the presence of oxygen, and the strain of yeast. In our study the date-juice isolate could grow in 
a wide $\mathrm{pH}$ range between 2 and 10, but $\mathrm{pH} 5.0$ was found to be the optimum $\mathrm{pH}$ for it. The grapes isolate showed growth at $\mathrm{pH} 3$ to 10 , but at $\mathrm{pH} 2$, it grow at a slow rate. One of the most important findings of this experiment was the ability to grow at high acidic condition by the date-juice isolate.

Both isolates in this study had resistance against high osmotic pressure. Both isolates showed highest growth at $6 \% \mathrm{NaCl}$ containing media. Growth gradually decreased at $15 \%$ and $20 \%$ $\mathrm{NaCl}$ containing media (Table 6).

Under shaking condition, the date-juice isolate showed highest ethanol production (5.93\%) in the presence of $6.5 \%$ and $7 \%$ glucose. The grapes isolate produced $5.93 \%$ ethanol in $6 \%$ glucose containing medium. Under non-shaking condition, the date-juice isolate showed 5.53\% ethanol production with $4 \%$ glucose and the grapes isolates produced maximum ethanol of $4.1 \%$ in the presence same glucose concentration (Table 7).

The 72 hours fermentation results showed the detailed characterization of the date-juice isolate, which proved to be the better isolate in every respect. A maximum of 7.75\% alcohol production was recorded after forty-eight hours in the presence of 6.5\% glucose and pH 6 (Table 7). This proved to be the highest production achieved in molasses media in this experiment.

\section{References}

1. Himmel ME, Ding SY, Johnson DK, Adney WS, Nimlos MR, Brady JW and Fourst TD. 2007. Biomass recalcitrance: Engineering plants and enzymes for biofuels production. Science. 315: 804-807.

2. Hánh-Hägerdal B, Galbe M, Gorwa-Grauslund MF, Lidén G and Zacchi G. 2006. Bio-ethanol - the Fuel of Tomorrow from the Residues of Today. Trends in Biotechnol. 24: 549-556.

3. Taherzadeh MJ and Karimi K. 2007. Process for ethanol from lignocellulosic materials I: Acid-based hydrolysis processes, BioResources. 2: 472-499.

4. Red•epoviæ S, Orliæ S Sikora S, Majdak A and Pretorius IS .2002.Identification and characterization of Saccharomyces cerevisiae andSaccharomyces paradoxus strains isolated from Croatian vineyards. Letters in Applied Microbiology. 35: 305 - 310

5. Boboye B and Dayo-Owoyemi I. 2009. Evaluation of dough sensory properties impacted by yeasts isolated form cassava. J. Applied Sci. 9: 771-776.

6. Alfenore S, Molina-Jouve C, Guillouet SE, Uribelarrea JL, Goma G and Benbadis L. 2007. Improving ethanol production and viability of Saccharomyces cerevisiae by a vitamin feeding strategy during fedbatchprocess. Appl. Microbiol. Biotechnol. 60: 67-72.

7. Fakruddin M, Quayum MA, Ahmed MM and Choudhury N. 2012. Analysis of key factors affecting ethanol production by Saccharomyces cerevisiae IFST-072011. Biotechnology. 11: 248-252.

8. Novick P and Botstein D. 1985. Phenotypic analysis of temperaturesensitive yeast actin mutants. Cell. 40: 405-416.

9. Miller GL. 1959. Use of dinitrosalicyclic acid reagent for determination of reducing sugar. Analytical Chem. 31: 426-28.

10. Conway EJ. 1939. Microdiffusion analysis and volumetric error. Corsby Lpckwood and Son, London.

11. Narendranath NV and Power R. 2005. Relationship between pH and medium dissolved solids in terms of growth and metabolism of Lactobacilli and Saccharomyces cerevisiae during ethanol production. Appl. Env. Microbiol. 71: 2239-2243.

12. Rodmui A, J. Kongkiattikajorn J and Dandusitapun Y. 2008. Optimization of agitation conditions for maximum ethanol production by co-culture. Kasetsart J. Nat. Sci. 42: 285-293.

13. Khan AR, Malek MA, Choudhury N and Khan SI. 1989. Alcohol production from molasses and liquid sugar using some indigenous yeast isolates. Bangladesh Jl of Microbiol. 6:37-42.

14. Borzani W, Garab A, Pires MH, Piplovic R and De IaHiguera GA. 1993. Batch ethanol fermentation of molasses: a correlation between the time necessary to complete the fermentation and the initial concentrations of sugar and yeast cells. World J Microbiol Biotechnol. 9: 265-68.Conway EJ (1939). Microdiffusion Analysis and Volumetric Error. Crosby Lockwood and Son, London

15. Apiradee Sripiromrak. 2006. Islolation and characterization of thermotolerant yeast for ethanol. M.Sc. Thesis Suranaree University of Technology.

16. Wayman M and Parekh SR. 1990. .Microbiology of fermentation catalysts. In: Biotechnology of Biomass Conversion. Milton Keynes: Open university press. pp. 75-100. 